\title{
Molecular detection of Candida species from hospitalized patients' specimens
}

\author{
José Luis Camacho-Cardoso', María Ángeles Martínez-Rivera', Patricia Manzano-Gayosso², \\ Luis Javier Méndez-Tovar ${ }^{3}$ Rubén López-Martínez² and Francisca Hernández-Hernández² \\ ${ }^{1}$ Laboratory of Medical Mycology, Department of Microbiology, Escuela Nacional de Ciencias Biológicas, Instituto Politécnico Nacional; ${ }^{2}$ Department \\ of Microbiology and Parasitology, Faculty of Medicine, Universidad Nacional Autónoma de México; ${ }^{3}$ Specialty Hospital, Centro Médico Nacional \\ Siglo XXI, Instituto Mexicano del Seguro Social, Mexico City, Mexico
}

\begin{abstract}
Objective: To identify the most frequent Candida species in specimens from patients hospitalized in different medical centers of Mexico City, with suspected fungal infection. Methods: Specimens were grown on Sabouraud dextrose agar at $28^{\circ} \mathrm{C}$ for $72 \mathrm{~h}$. In addition, DNA was extracted. Isolates were grown on CHROMagar Candida ${ }^{T M}$, at $37^{\circ} \mathrm{C}$ for $48 \mathrm{~h}$. The molecular identification was performed by polymerase chain reaction (PCR) using primers specific for four species. Results: Eighty one specimens were processed and included: bronchial lavage, pleural, cerebrospinal, peritoneal, ascites and bile fluids; blood, sputum, bone marrow, oro-tracheal cannula and ganglion. By culture, 30 samples (37\%) were positive, and by PCR, 41 (50.6\%). By PCR, the frequency of species was: Candida albicans $82.9 \%$, Candida tropicalis $31.7 \%$, Candida glabrata $24.4 \%$, and Candida parapsilosis $4.9 \%$. In $34.1 \%$ of specimens a species mixture was detected suggesting a co-infection: Two species in five specimens (C. albicans-C tropicalis and C. albicans-C glabrata), and three species in three specimens (C. albicans-C. glabrata-C. tropicalis). Conclusions: The PCR is an useful tool for detection the most common Candida species causing infection in hospitalized patients, it avoids the requirement of culture weather we start from clinical specimen and it favors the early diagnosis of invasive candidiasis.
\end{abstract}

KEY WORDS: Candida albicans. Candida tropicalis. Candida glabrata. Candida spp. Invasive candidiasis. Polimerase chain reaction. CHROMagar Candida ${ }^{T M}$.

\section{Introduction}

The Candida genus is comprised by various species potentially causative of candidiasis, a mycosis of variable clinical expression (superficial, mucocutaneous and invasive infection), the frequency of which has increased over the last three decades owing to an increase in risk factors in immunocompromised patients ${ }^{1-4}$
Invasive candidiasis is the most important fungal-origin hospital-acquired infection owing to its frequency and seriousness, with lethality indices $\geq 40 \%$. Main opportunistic infection risk factors associated with this infection include diabetes mellitus, human immunodeficiency virus (HIV) infection/AIDS, neutropenia-associated fever, neoplasms, prolonged indwelling venous or urinary catheter, cardiac valves, steroid prolonged use, use of broad spectrum steroids and

\section{Correspondence:}

Francisca Hernández-Hernández

Facultad de Medicina

Av. Universidad No. 3000

Col. Universidad Nacional Autónoma de México, C. U.

Del. Coyoacán

C.P. 04510, Ciudad de México, México

E-mail: frank-hh@ @comunidad.unam.mx
Date of reception: 06-04-2016

Date of acceptance: 07-04-2016

DOI://dx.doi.org/10.24875/GMM.M18000045
Gac Med Mex. 2017;153:528-536

Contents available at PubMed www.gacetamedicademexico.com 
immunosuppressants, surgery and solid organ transplantation ${ }^{2,4-7}$.

Among more than 150 described Candida species, only about 15 have been isolated from patients as infectious agents ${ }^{8}$. Candida albicans remains the most common agent associated with hospital-acquired infections, followed by Candida tropicalis, Candida parapsilosis, Candida glabrata and Candida krusei. The importance of identifying fungal species involved in infection lies in that some of them have innate resistance to some antifungals $\mathrm{s}^{4,6,7,9,10}$.

Invasive candidiasis diagnosis is difficult because signs and symptoms are unspecific, as well as due to the fact that these opportunistic yeasts dwell mainly in mucosae in humans ${ }^{11}$. Clinical laboratory conventional procedures to diagnose invasive candidiasis include morphological and biochemical studies, such as smear, culture, histopathology, serology and, sometimes, the use of specific fluorescent antibodies ${ }^{1,3,12-14}$. However, sensitivity and specificity of these methods are low. In neutropenic patients, yeasts are detected by culture or histopathology approximately 120-140 days after the detection of this predisposing factor, which results in late specific therapy ${ }^{11}$. For some authors, culture is the reference method for invasive candidiasis diagnosis ${ }^{15}$. With the purpose to attain a quicker and more specific diagnosis in order to establish a successful therapy, molecular procedures, such as polymerase chain reaction (PCR) and its variants have been developed and applied in the past few years, with results that are superior to those with conventional procedures in time, sensitivity and specificity ${ }^{9,12,16,17}$. Recently, mass spectrometry has emerged as a quick and reliable laboratory technique that can be used as an alternative procedure for the identification of fungi ${ }^{10,14,18}$.

In Mexico there are only few studies reporting the frequency of Candida spp isolation in clinical samples, and these reports are even scarcer in Mexico City hospital centers. Main Candida species associated with invasive candidiasis are C. albicans, C. tropicalis, C. glabrata and C. parapsilosis. The purpose of this work was to detect the four more relevant Candida species directly in clinical specimens obtained from patients hospitalized at different centers of Mexico City with suspected fungal infection and this way contribute to invasive candidiasis early diagnosis.

\section{Methods}

Biological specimens were requested from different hospital centers of Mexico City, which were obtained from hospitalized patients with one or more opportunistic infection risk factors, clinical suspicion of invasive mycosis or indeterminate diagnosis associated with fever of unknown origin. Eighty-one samples were received and processed, all of them submitted by the corresponding Central Laboratory: 11 by the Infectology Hospital of the Centro Médico La Raza of the Instituto Mexicano del Seguro Social (IMSS); 20 by the Hospital Regional General Ignacio Zaragoza, of the Instituto de Seguridad y Servicios Sociales para los Trabajadores del Estado (ISSSTE), 28 by the Specialty Hospital of the Centro Médico Nacional Siglo XXI, IMSS; one by the Hospital General Dr. Darío Fernández Fierro, ISSSTE; and 21 by the Hospital General de México Eduardo Liceaga of the Ministry of Health.

All clinical samples were cultured in Sabouraud dextrose agar (SDA) without antibiotics and incubated at $28{ }^{\circ} \mathrm{C}$ for 72 hours. The number of colony-forming units (CFU) was recorded. Sputum cultures that had yeast-like growth were considered positive when they had $\geq 1 \times 10^{4} \mathrm{CFU}$. For sterile samples, any yeast-like growth was regarded as positive. Cultures that were positive in SDA were re-seeded in CHROMagar Candida $^{\mathrm{TM}}$ and incubated for 72 hours at $37{ }^{\circ} \mathrm{C}$ in darkness, with the purpose to establish a presumptive identification of one or more species involved in the infectious process, according to the color of the colony; for these isolates, DNA extraction was not necessary.

C. albicans ATCC 64550, C. glabrata ATCC 90030 , C. tropicalis ATCC 750 and C. parapsilosis ATCC 29019 were included as reference strains. These strains were seeded in yeast extract peptone dextrose (YPD) medium and incubated for 48 hours at $37^{\circ} \mathrm{C}$. DNA extraction was carried out using the Blin and Stanford method ${ }^{19}$. DNA was treated with RNAse A $\left(10 \mu \mathrm{g} / \mathrm{mL}\right.$, Invitrogen $\left.{ }^{\circledR}\right)$ according to the manufacturer's instructions, and purified, re-suspended in sterile deionized water and quantified by spectrophotometry. These reference strains' DNA was only used to standardize the PCR technique.

For whole blood DNA extraction, the procedure recommended by Loffler et al. ${ }^{20}$ was followed. $1 \mathrm{~mL}$ of whole blood was added $1 \mathrm{~mL}$ of erythrocyte lysis buffer (Tris $\mathrm{HCl} 10 \mathrm{mM} \mathrm{pH} 7.6, \mathrm{MgCl}_{2} 5 \mathrm{mM}, \mathrm{NaCl} 10$ $\mathrm{mM}$ ) and the mixture was incubated in ice for $15 \mathrm{~min}$ utes; then, it was centrifuged at $13,000 \mathrm{~g}$ for $15 \mathrm{~min}$ utes. The sediment was added $1 \mathrm{ml}$ of leukocyte lysis buffer (Tris $\mathrm{HCl} 10 \mathrm{mM} \mathrm{pH} \mathrm{7.6,} \mathrm{EDTA} 10 \mathrm{mM}, \mathrm{NaCl} 50$ $\mathrm{mM}, 0.2 \% \mathrm{SDS}$ ) and proteinase $\mathrm{K}$ (final concentration, 
Tabla 1. Primers used to amplify Candida species ITS1/ITS2 region ${ }^{16}$

\begin{tabular}{|c|c|c|c|c|}
\hline Species & Primer & Sequences (5'-3') & Amplicon size (bp) & GenBank access no. \\
\hline Candida albicans & $\begin{array}{l}\text { CAL1 } \\
\text { CAL2 }\end{array}$ & $\begin{array}{l}\text { ttc atc aac ttg tca cac cag a } \\
\text { atc ccg cct tac cac tac cg }\end{array}$ & $\approx 273$ & L47111, L28817 \\
\hline Candida glabrata & $\begin{array}{l}\text { CGL1 } \\
\text { CGL2 }\end{array}$ & $\begin{array}{l}\text { tta tca cac gac tcg cac ct } \\
\text { ccc aca tac tga tat ggc cta caa }\end{array}$ & $\approx 423$ & AB032177, AF167993 \\
\hline Candida parapsilosis & $\begin{array}{l}\mathrm{CPA}^{*} \\
\mathrm{CPA}^{+} \\
\mathrm{CPA} 2\end{array}$ & $\begin{array}{l}\text { ttg gta ggc ctt cta tat ggg } \\
\text { gcc aga gat taa act caa cca a } \\
\text { cct atc cat tag ttt ata ctc cgc }\end{array}$ & $\approx 320 \approx 300$ & AF287909, L47109 \\
\hline Candida tropicalis & $\begin{array}{l}\text { CTR1 } \\
\text { CTR2 }\end{array}$ & $\begin{array}{l}\text { caa tcc tac cgc cag agg tta t } \\
\text { tgg cca cta gca aaa taa gcg t }\end{array}$ & $\approx 357$ & AF287910, AF268095 \\
\hline
\end{tabular}

$200 \mu \mathrm{g} / \mu \mathrm{L}$. The mixture was incubated at $65{ }^{\circ} \mathrm{C}$ for 60 minutes. It was then centrifuged at $13,000 \mathrm{~g}$ for 15 minutes. The supernatant was discarded and the sediment was used for DNA extraction using the QIAamp DNA mini kit.

For DNA extraction from other bodily fluids, the procedure by Loffler et al. ${ }^{20}$ was followed. $1 \mathrm{~mL}$ of sample was centrifuged at $13,000 \mathrm{~g}$ for 5 minutes. The sediment was recovered and added $650 \mu \mathrm{L}$ of lyticase

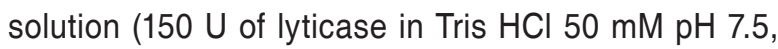
EDTA $10 \mathrm{mM} \mathrm{pH} 7.8$ and $\beta$ mercaptoethanol $28 \mathrm{mM}$ ). The mixture was incubated at $37{ }^{\circ} \mathrm{C}$ for 45 minutes and centrifuged at $13,000 \mathrm{~g}$ for 15 minutes. The sediment was re-suspended in TE buffer, and the DNA was extracted with the QIA DNA mini kit, following the manufacturer's instructions. The DNA was stored at $-20^{\circ} \mathrm{C}$ until its use for PCR.

The DNA obtained both from the reference strains (for PCR standardization) and clinical specimens (for the detection of Candida species) was used to perform the PCR assay with specific primers for each species, according to Luo and Mitchell ${ }^{16}$ (Table 1).

According to the conditions proposed by Luo and Mitchell ${ }^{16}$, the reaction mixture contained $1 \mathrm{ng}$ of DNA, $\mathrm{MgCl} 1.5 \mathrm{mM}$, dNTPs $0.2 \mathrm{mM}$, oligonucleotides 0.5 $\mu \mathrm{M}$ and Taq polymerase $0.5 \mathrm{U}$. Amplification conditions consisted in initial denaturalization at $96{ }^{\circ} \mathrm{C}$ for 5 minutes; 40 denaturalization cycles at $94{ }^{\circ} \mathrm{C}$ for 30 seconds; alignment at $58{ }^{\circ} \mathrm{C}$ for 30 seconds; and polymerization at $72{ }^{\circ} \mathrm{C}$ for 30 seconds. A final extension at $72{ }^{\circ} \mathrm{C}$ for 15 minutes was favored. Amplicons were separated by electrophoresis in 1.5\% agarose gel, stained with ethidium bromide. After standardization with the reference strains, the Candida species was determined according to the size of the obtained amplicon (Table 1).
From a 24-hour culture of $C$. albicans, C. tropicalis, C. glabrata and C. parapsilosis in SDA, a suspension was prepared and added to $500 \mu \mathrm{L}$ of whole blood/ EDTA obtained from a healthy individual, in such a way that the amount of yeasts to determine PCR sensitivity in this biological product was $5,10,50,100$ and 500 cells in $500 \mu \mathrm{L}$. This mixture was processed for DNA extraction and for PCR following the previously described procedures. The lower limit of DNA detection using the different amounts of yeasts in whole blood samples was 100 cells/500 $\mu \mathrm{L}$ for each one of the four species.

\section{Results}

Figure 1 shows the amplification products obtained with DNA of the four Candida reference species, using species-specific primers. The observed amplicon size was just as expected.

All 81 processed clinical samples belonged to adults aged between 20 and 70 years, out of which $64.5 \%$ were men and $35.5 \%$ were women, and included 25 bronchoalveolar lavage fluid (BALF), 19 blood, 15 sputum, 7 pleural fluid, 3 peritoneal fluid, 3 ascites fluid, 2 cerebrospinal fluid, 2 urine, 1 gallbladder fluid, 1 ulcer secretion, 1 bone marrow, 1 orotracheal intubation cannula and 1 lymph node samples. Most patients $(67.5 \%)$ had been diagnosed with pneumonia, a minority with pulmonary tuberculosis $(6.1 \%)$, and the rest had other diagnoses. Of the 19 blood samples, 17 corresponded to patients diagnosed with fever of unknown origin. Considering the three most common biological products, of the 25 BALF, 16 whole blood and 15 sputum samples, 20 (80\%), $3(15.7 \%)$ and $14(93.3 \%)$, respectively, were positive by culture or PCR (or by both methods). 


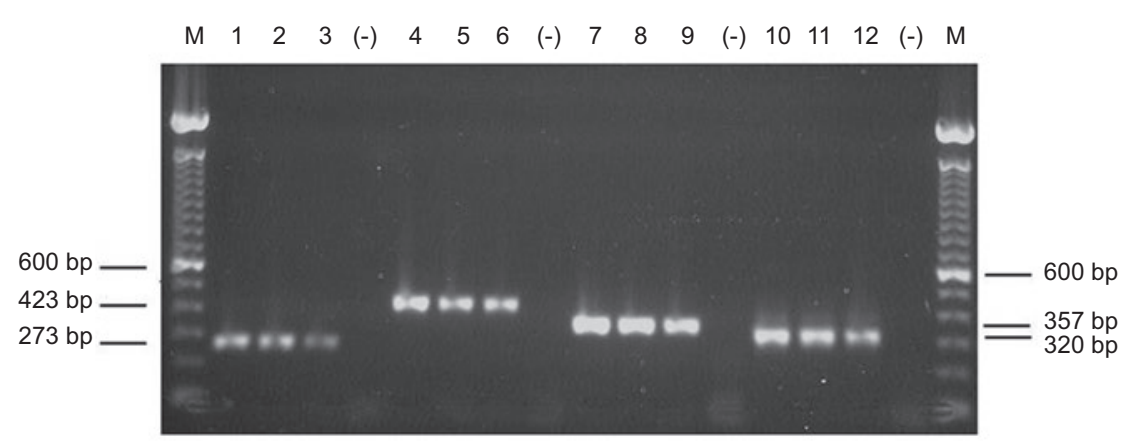

Figure 1. Reference strains (C. albicans, lanes 1-3; C. glabrata, lanes 4-6; C. tropicalis, lanes 7-9; and C. parapsilosis, lanes 10-12) ITS1 and ITS2 regions amplification products. 100, 10 and $1 \mathrm{ng}$ of total DNA were used for each species. M: 100-bp marker. (-): negative controls.

Table 2 shows the comparative result of BALF samples that were positive by culture and PCR and, in table 3 , the result corresponding to other bodily fluids can be observed. Of the 81 samples, 30 (37\%) were positive for Candida spp. by culture in SDA, and one culture corresponded to Cryptococcus sp.

Among the cultures in CHROMagar Candida ${ }^{\mathrm{TM}}$, the most commonly isolated species was $C$. albicans (24/30, $80 \%)$, followed by C. glabrata and C. tropicalis (4/30, $13.3 \%$ each). C. parapsilosis was not identified in this medium. In three cases (10\%), association of two species was identified: one of $C$. tropicalis with $C$. krusei and two of $C$. albicans with $C$. tropicalis.

By PCR, 41 (50.6\%) Candida spp.-positive samples were detected. The most common species was $C$. albicans (82.9\%), followed by C. tropicalis (31.7\%), C. glabrata $(24.4 \%)$ and C. parapsilosis $(4.9 \%)$. In 14 cases $(34.1 \%)$, two or three species were observed. Predominant two-species combinations were: 5 cases of C. albicans with C. tropicalis and 3 cases of C. albicans with $C$. glabrata. With regard to the mixture of three species, C. albicans, C. glabrata and C. tropicalis were predominant, with 3 cases.

Comparing the results obtained for Candida species identification by culture in CHROMagar Candida ${ }^{\mathrm{TM}}$ and by PCR, the culture showed a total of 12 false negatives. When a species was identified in this medium, it was also detected by PCR. By culture in CHROMagar Candida ${ }^{\mathrm{TM}}$, association of two species was observed in 3 cases, and by PCR, association of 2 or 3 species was found in 14 cases. These results demonstrate the higher sensitivity, specificity and quickness of the PCR technique when compared with culture in CHROMagar Candida ${ }^{\mathrm{T}}$.

Figure 2 shows some amplified products of the four Candida species obtained from clinical samples with Candida spp.-specific primers.
One sputum sample was positive by culture in SDA, identified as C. glabrata in CHROMagar Candida ${ }^{\mathrm{TM}}$ and negative by PCR.

Figure 3 shows the results obtained by culture and by PCR for each one of the Candida species. The difference in positivity of each procedure is directly related to the frequency all four species were identified with.

\section{Discussion}

Candida spp. infections are the cause of great morbidity and mortality in patients with any associated opportunistic infection risk factor, and their diagnosis must therefore be quick and reliable in order to establish an efficacious and opportune treatment.

Currently, some authors consider culture to be the reference method for invasive candidiasis diagnosis, particularly from sterile samples ${ }^{15}$. For other authors, this procedure is not entirely reliable, particularly because, as it involves the use of blood samples, up to $50 \%$ of them are negative and the time it takes to obtain the result is 3 days or more $e^{9,12,14}$. Molecular results have shown to be quicker and more sensitive, specific and reliable than phenotypical methods ${ }^{17,18}$. In the present study, specific PCR was used to determine the frequency of all four Candida species reported as more commonly affecting patients that are hospitalized for different causes.

Considering the origin of the specimens, the highest positivity percentage, both by culture and by PCR (93.3\%), corresponded to sputum, the only non-sterile product processed in this study. Most patients of whom these samples came from had a previous diagnosis of infection (pneumonia, pulmonary abscess, tuberculosis or HIV infection) and, therefore, based on 
Tabla 2. Candida spp. detection in bronchioalveolar lavage fluid processed by culture and species-specific PCR

\begin{tabular}{|c|c|c|c|c|}
\hline Sample & Previous diagnosis & Culture in SDA & Culture in CHROMagar Candida ${ }^{\mathrm{TM}}$ & Species-specific PCR \\
\hline BALF 08-193 & Pneumonia & Negative & Negative & C. albicans \\
\hline 170 & Pneumonia & Positive & C. albicans & C. albicans \\
\hline 105 & CVD & Positive & C. glabrata & $\begin{array}{l}\text { C. albicans, } \\
\text { C. glabrata }\end{array}$ \\
\hline $08-275$ & Pulmonary mycosis & Positive & C. tropicalis & C. tropicalis \\
\hline $628-08$ & Pneumonia & Negative & Negative & C. albicans \\
\hline 416 & Pneumonia & Positive & C. albicans & C. albicans \\
\hline $485-08$ & Pneumonia & Negative & Negative & $\begin{array}{l}\text { C. albicans, } \\
\text { C. glabrata, } \\
\text { C. tropicalis }\end{array}$ \\
\hline 74 & Pneumonia & Negativo & Negative & C. tropicalis \\
\hline 1981 & Pneumonia & Negative & Negative & C. albicans \\
\hline 43 & Pneumonia & Positive & C. albicans & $\begin{array}{l}\text { C. albicans, } \\
\text { C. tropicalis }\end{array}$ \\
\hline $676-08$ & Pneumonia & Positive & C. albicans & $\begin{array}{l}\text { C. albicans, } \\
\text { C. glabrata }\end{array}$ \\
\hline 1979 & Pneumonia & Negative & Negative & $\begin{array}{l}\text { C. albicans, } \\
\text { C. glabrata }\end{array}$ \\
\hline 101 & CVD & Positive & C. albicans & C. albicans \\
\hline 511 & Pneumonia & Positive & C. albicans & $\begin{array}{l}\text { C. albicans, } \\
\text { C. tropicalis }\end{array}$ \\
\hline $1012-08$ & Pneumonia & Positive & C. albicans & C. albicans \\
\hline $08-512$ & RT, Pneumonia & Negative & Negativo & C. albicans \\
\hline $08-505$ & HIV/ mycosis & Positive & C. albicans & C. glabrata \\
\hline C108 & Pneumonia & Positive & C. albicans & C. albicans \\
\hline $\mathrm{C} 23$ & Pneumonia & Positive & C. albicans & C. albicans \\
\hline 81 & Pneumonia & Positive & C. glabrata & C. glabrata \\
\hline
\end{tabular}

BALF: bronchoalveolar lavage fluid; CVD: cerebrovascular disease; HIV: human immunodeficiency virus; PCR: polymerase chain reaction; RT: renal transplantation; SDA: Sabouraud dextrose agar.

the elevated number of yeasts detected by culture in SDA, we consider that a high number of them had an overt Candida infection.

BALF samples showed higher positivity by PCR $(80 \%)$ than by culture in SDA $(52 \%)$. This difference could partially be attributed to the fact that specific or unspecific immune response of the host might exert a fungicidal or fungistatic effect on yeasts, which would prevent their development. Schabereiter-Gurtner et al. ${ }^{21}$ found $19.4 \%$ of false negatives in cultures of different Candida spp. and Aspergillus spp. specimens in comparison with real-time PCR. Antifungal treatment prior to sample-taking might also have a direct effect on yeasts' growth inhibition ${ }^{17,22}$.
All 19 blood samples were negative by SDA culture and had a low percentage of positivity by PCR (15.7\%). False negatives have been attributed to PCR-inhibitory substances, such as hemoglobin and lactoferrin, usually associated with erythrocytes and leukocytes, respectively ${ }^{23}$. In contrast with our results, several authors have found that blood culture positivity ranges from 50 to $60 \%$ of cases $^{24}$. In a study of patients with fever of unknown origin, Méndez et al. ${ }^{25}$ found that $35 \%$ had some fungal infection, mainly candidiasis, and considering this type of infections is therefore necessary in the presumptive diagnosis.

Both processed urine samples were positive by culture in SDA and by PCR. Although candiduria is not a 


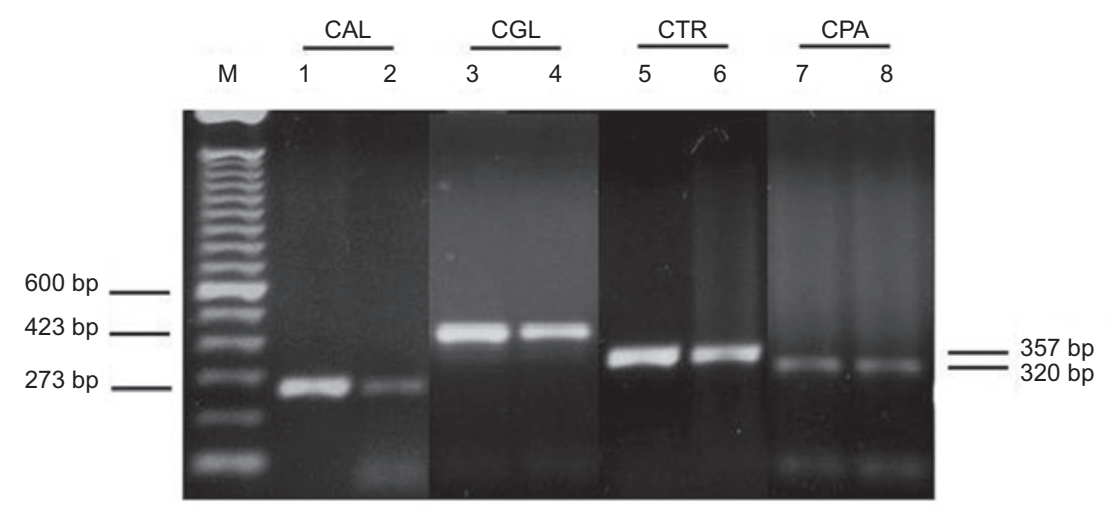

Figure 2. Amplification products of regions ITS1 and ITS2 of the four Candida species retrieved from clinical samples. M: 100-bp marker. Lane 1: 511; lane 2: 08-512; lane 3: C11; lane 4: 2719; lane 5: 485-08; lane 6: 08-505; lane 7: 1151-08; lane 8: 512.

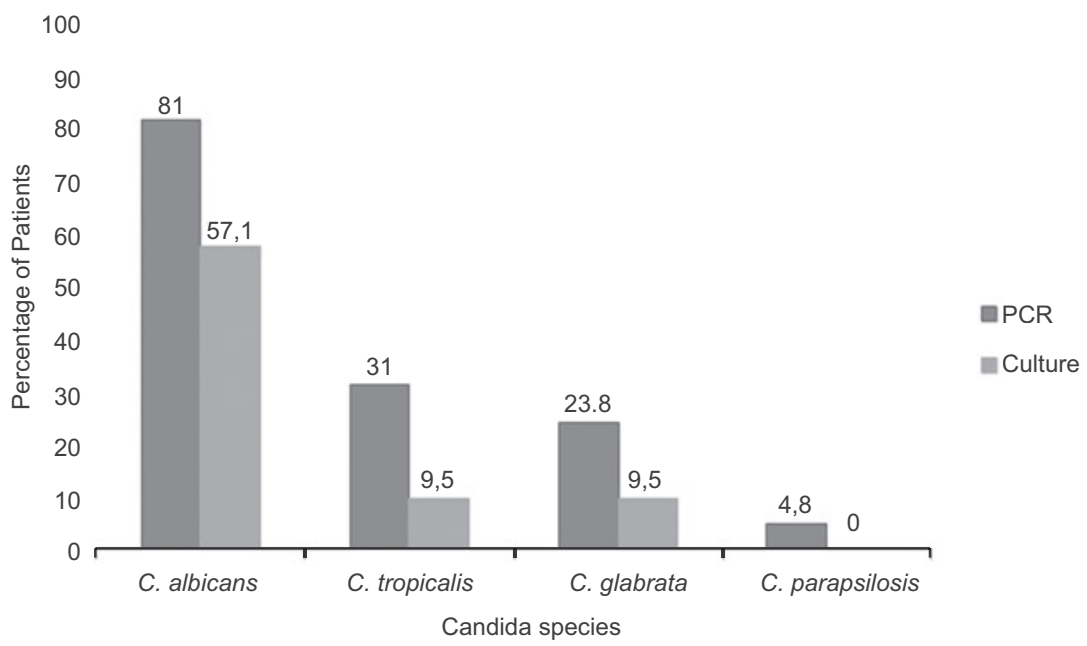

Figure 3. Correlation between PCR and culture results for the detection of each one of the Candida species $(n=81)$.

candidiasis-specific indicator, it has been proposed as an indicator of poor prognosis in old age patients, as a consequence of other associated conditions. Severely-ill patients' (prolonged stay at the intensive care unit, pre-term infants, patients with burns or transplant recipients) positive urine cultures are particularly important, since they can precede candidemia or be indicative of severe renal candidiasis ${ }^{12,24}$.

With regard to species' distribution by both methods, C. albicans was more commonly detected, followed by $C$. tropicalis and C. glabrata. This frequency is equal to that reported by other Mexican authors that have used similar methodology ${ }^{9}$. In a study carried out by Hernández et al. ${ }^{26}$, using phenotypycal methods with different biological products, a frequency of $C$. parapsilosis isolation of $68.6 \%$ was reported, followed by C. albicans $(8.6 \%)^{26}$. In a 3-year surveillance study (2004-2007) with Candida isolates obtained from patients of hospital centers from Monterrey (Mexico), and using phenotypical studies,
González et al. ${ }^{27}$ reported C. parapsilosis as the species most commonly isolated from blood (37.9\%), followed by C. albicans $(31.9 \%)$, C. tropicalis $(14.8 \%)$ and C. glabrata (8\%), mainly in pediatric population who were catheter carriers. The present work included only adult population, and C. parapsilosis was identified at a low percentage only by PCR (4.9\%), since this is a species that is not identified by culture in CHROMagar Candida ${ }^{\mathrm{TM}}$.

CHROMagar Candida ${ }^{\mathrm{TM}}$ is a simple and relatively inexpensive technique in the mycological diagnostic laboratory. It has as advantage that it detects mixtures of species and provides, in a maximum of 72 hours, presumptive identification of some Candida species (C. albicans, C. glabrata, C. tropicalis and C. krusei $)^{9,13}$. In this work, only in 3 cases $(10 \%)$ was a mixture of species detected in this medium.

PCR was notoriously superior in the detection of mixtures of species (34.1\%) with regard to CHROMagar Candida ${ }^{\mathrm{TM}}$. Associations of two and three 
Gaceta Médica de México. 2017;153

Tabla 3. Candida spp. detection in different samples by culture and species-specific PCR

\begin{tabular}{|c|c|c|c|c|}
\hline Sample & Previous diagnosis & Culture in SDA & Culture in CHROMagar Candida ${ }^{\mathrm{TM}}$ & Species-specific PCR \\
\hline Sputum 171 & Pneumonia & Positive & C. albicans & C. albicans \\
\hline 188 & AP & Positive & C. glabrata & C. glabrata, C. tropicalis \\
\hline 248 & $\mathrm{~Tb}$ & Positive & C. albicans & C. albicans \\
\hline $496-08$ & Pneumonia & Positive & C. albicans & C. albicans, C. tropicalis \\
\hline $617-08$ & Pneumonia & Positive & C. albicans & C. albicans \\
\hline 459 & $\mathrm{~Tb}$ & Positive & C. albicans & C. albicans \\
\hline 460 & HIV & Positive & C. albicans & C. albicans \\
\hline 426 & HIV & Positive & C. albicans & C. albicans \\
\hline $656-08$ & Pneumonia & Positive & C. albicans & C. albicans \\
\hline 519 & Pneumonia & Positive & $\begin{array}{l}\text { C. tropicalis, } \\
\text { C. krusei }\end{array}$ & $\begin{array}{l}\text { C. glabrata, C. tropicalis, } \\
\text { C. parapsilosis }\end{array}$ \\
\hline 543 & Pneumonia & Positive & C. albicans & C. albicans, C. tropicalis \\
\hline 2719 & Pneumonia & Positive & $\begin{array}{l}\text { C. albicans, } \\
\text { C. tropicalis }\end{array}$ & $\begin{array}{l}\text { C. albicans, C. glabrata, } \\
\text { C. tropicalis }\end{array}$ \\
\hline $1151-08$ & Pneumonia & Positive & C. albicans & C. albicans, C. parapsilosis \\
\hline 289 & $\mathrm{~Tb}$ & Positive & C. glabrata & Negativo \\
\hline Blood C547 & FUO & Negative & Negative & C. albicans \\
\hline 19 & FUD & Negative & Negative & C. albicans \\
\hline 23 & FUO & Negative & Negative & C. albicans \\
\hline Urine 536-08 & ND & Positive & C. albicans & C. albicans \\
\hline C11 & ND & Positive & $\begin{array}{l}\text { C. albicans } \\
\text { C. tropicalis }\end{array}$ & $\begin{array}{l}\text { C. albicans, C. tropicalis, } \\
\text { C. glabrata }\end{array}$ \\
\hline Pleural fluid 662 & $\begin{array}{l}\text { Enteropathy, } \\
\text { Pneumonia }\end{array}$ & Negative & Negative & C. albicans \\
\hline Bile 2508 & Septicemia & Positive & C. albicans & C. albicans, C. tropicalis \\
\hline Lymph node 825 & $\mathrm{HIV}, \mathrm{Tb}$ & Negative & Negativo & C. tropicalis \\
\hline CSF & Meningitis & Positive & $N D^{*}$ & Negativo \\
\hline
\end{tabular}

*Round-shaped, capsulated yeasts were observed on microscopic examination with Chinese ink.

CSF: cerebrospinal fluid; FUO: fever of unknown origin; HIV: human immunodeficiency virus; ND: not determined; PA: pulmonary abscess; PCR: polymerase chain reaction; SDA: Sabouraud dextrose agar Tb: tuberculosis.

species were detected in single biological samples. Detection of co-infections with two or more species has also been reported by other authors ${ }^{28-30}$. The detection of mixtures is useful for choosing an adequate treatment, since one or more species might be resistant to one or more antifungals, which might lead to the administration of an inadequate therapy and hence favor resistance selection and etiological agents dissemination ${ }^{13,14}$. Currently, PCR is also a useful tool for the detection of strains that are resistant to antifungals of therapeutic use $e^{9,14,18}$.
C. albicans is the predominant species as candidiasis causative agent. This microorganism represents a serious public health problem with clinical relevance owing to its high rate of morbidity and mortality $2,4,7,30$. It is relevant, in addition to its high frequency, because an increase in the appearance of azole compounds-resistant strains has been detected in the past few years ${ }^{15,31,32}$.

In the USA, $C$. tropicalis is the fourth systemic candidiasis causative species, while in Latin America it is the second ${ }^{4,6}$. There are reports referring that 
C. tropicalis rapidly acquires resistance during azole therapy ${ }^{21}$.

C. glabrata is known to have intrinsic resistance to fluconazole and cross-resistance to other azoles ${ }^{4,13,24}$. This species often causes infections in patients on prophylactic therapy with azoles $6,27,30$.

Although $C$. parapsilosis is an exogenous pathogen that has been found in normal skin, this species is involved in systemic infections, particularly in newborns $^{7,24}$. In Latin America, C. parapsilosis has been found in patients of all ages ${ }^{4}$. At lower proportion than other species, C. parapsilosis has also developed resistance to azole compounds of common use in antifungal therapy ${ }^{31}$.

Among current methods to establish the invasive candidiasis diagnosis, the US Food and Drug Administration has approved four:

- Matrix-assisted Laser Desorption/Ionization Time-of-Flight (MALDI-TOF) is a procedure that uses mass spectroscopy and requires a yeast pure culture that may take from 24 to 48 hours. After this time, the result can be known in 1015 minutes, with the advantage that it identifies most Candida species.

- Peptide Nucleic Acid Fluorescent in Situ Hybridization (PNA-FISH) doesn't necessarily require a pure culture, and only provides two paired results: C. albicans/C. tropicalis and C. glabrata/C. kruseilC. parapsilosis (it doesn't provide information for a single species). It is available as a commercial kit.

- The $\beta$-D-glucan test detects this fungal wall component in blood, and it is therefore a panfungal test (Candida spp., Aspergillus spp., Pneumocystis jirovecii, demiatiaceous fungi and several more). It requires two positive results for confirmation. It is an unspecific, expensive and tedious test, and has therefore not been widely accepted.

- T2Candida is a PCR-based test that uses magnetic resonance to detect Candida spp. in whole blood. It provides pair-wise results, just as PNA$\mathrm{FISH}$. Once blood is processed (erythrocyte chemical and mechanical lysis), the result is available in 3-4 hours $^{15}$.

According to our results, species-specific PCR showed four main advantages with regard to culture: 1) $13 \%$ more positive results were obtained; 2 ) it is a quick procedure, since the time elapsed since the specimen is received until the result for the four most common species is obtained is 6 hours, whereas waiting time for a culture is 48-72 hours; 3 ) it enables the detection of mixtures of up to three species, whereas with CHROMagar Candida ${ }^{\mathrm{TM}}$, only two-species mixtures were detected; and 4) although the cost is higher than that of culture (estimated at MXP 560.00 , USD 31.10 for the four species), it is low if the cost undiagnosed or wrongly treated candidiasis would imply is taken into account. These characteristics lend support to the proposal for using this technique as a procedure that identifies $80 \%$ of the species that cause invasive candidiasis, a disease that in Mexico has not been sufficiently explored.

\section{Funding}

This work was carried out with financial support of PAPIT (Programa de Apoyo a Proyectos de Investigación e Innovación Tecnologica), of the General Directorate of Academic Personnel Affairs, UNAM (Project Code Number: IN224006).

José Luis Camacho Cardoso was a CONACYT grant recipient for this work (Support number 205279).

María Ángeles Martínez Rivera is recipient of grants presented by the Instituto Politécnico Nacional (IPN) EDI, COFFAA and CONACYT Sistema Nacional de Investigadores (SNI).

\section{Acknowledgements}

We thank all people who provided us clinical samples: Rocío López, MSc, Hospital General Ignacio Zaragoza, ISSSTE; Alexandro Bonifaz, MSc, Hospital General de México Dr. Eduardo Liceaga; and Rosa María Cervantes, Chemistry, Bacteriology and Parasitology M.S., Infectology Hospital, Centro Médico La Raza, IMSS.

\section{References}

1. Linton CJ, Borman AM, Cheung G, et al. Molecular identification of unusual pathogenic yeast isolates by large ribosomal subunit gene sequencing: 2 years of experience at the United Kingdom mycology reference laboratory. J Clin Microbiol. 2007;45:1152-8.

2. Falagas ME, Roussos N, Vardakas KZ. Relative frequency of albicans and the various non-albicans Candida spp among candidemia isolates from inpatients in various parts of the world: a systematic review. Int $J$ Infect Dis. 2010;14: e954-66.

3. Aittakorpi A, Kuusela P, Koukila-Kahkola $P$, et al. Accurate and rapid identification of Candida spp. frequently associated with fungemia by using PCR and the microarray-based prove-it sepsis assay. J Clin Microbiol. 2012;50:3635-40

4. Sardi JSO, Scorzoni L, Bernardi T, et al. Candida species: current epidemiology, pathogenicity, biofilm formation, natural antifungal products and new therapeutic options. J Med Microbiol. 2013;62:10-24.

5. Armstrong-James D. Invasive Candida species infection: the importance of adequate empirical antifungal therapy. J Antimicrob Chemother. 2007;60:459-60

6. Pfaller MA, Diekema DJ. Epidemiology of invasive candidiasis: a persistent public health problem. Clin Microbiol Rev. 2007;20:133-63. 
7. Guinea J. Global trends in the distribution of Candida species causing candidemia. Clin Microbiol Infect. 2014;20:5-10.

8. Yapar N. Epidemiology and risk factors for invasive candidiasis. The Clin Risk Manag. 2014;10:95-105.

9. Estrada-Barraza D, Dávalos-Martínez A, Flores-Padilla L, et al. Comparación entre métodos convencionales, CHROMagar Candida y el método de la PCR para la identificación de especies de Candida en aislamientos clínicos. Rev lberoam Micol. 2011;28:36-42.

10. Durán-Valle MT, Sanz-Rodríguez N, Muñoz-Paraíso C, et al. Identification of clinical yeasts by Vitek MS system compared with API ID $32 \mathrm{C}$. Med Mycol. 2014;52:342-9.

11. Pontón J. Utilidad de los marcadores biológicos en el diagnóstico de la candidiasis invasora. Rev Iberoam Micol. 2009;26:8-14.

12. Ellepola ANB, Morrison CJ. Laboratory diagnosis of invasive candidiasis. J Microbiol. 2005:43:65-84.

13. Pincus DH, Orenga S, Chatellier S. Yeast identification - past, present, and future methods. Med Mycol. 2007;45:97-121.

14. Lopes-Colombo A, Cortes JA, Zurita J, et al. Recommendations for the diagnosis of candidemia in Latin America. Rev Iberoam Micol. 2013;30:150-7.

15. McCarty TP, Pappas PG. Invasive candidiasis. Infect Dis Clin North Am. 2016;30:103-24.

16. Luo G, Mitchell TG. Rapid identification of pathogenic fungi directly from cultures by using multiplex PCR. J Clin Microbiol. 2002;40:2860-5.

17. Buitrago MJ, Aguado JM, Ballen A, et al. Efficacy of DNA amplification in tissue biopsy samples to improve the detection of invasive fungal disease. Clin Microbiol Infect. 2012;19:E271-77.

18. Arvanitis M, Anagnostou T, Fuchs BB, et al. Molecular and nonmolecular diagnostic methods for invasive fungal infections. Clin Microbiol Rev. 2014;27:490-526

19. Blin N, Stafford DW. A general method for isolation of high molecular weight DNA from eukaryotes. Nucleic Acids Res. 1976;3:2303-8.

20. Loffler J, Hebart H, Schumacher U, et al. Comparison of different methods for extraction of DNA of fungal pathogens from cultures and blood. J Clin Microbiol. 1997;35:3311-2.

21. Schabereiter-Gurtner C, Selitsch B, Rotter ML, et al. Development of novel real-time PCR assays for detection and differentiation of eleven medically important Aspergillus and Candida species in clinical specimens. J Clin Microbiol. 2007;45:906-14.
22. Guery BP, Arendrup MC, Auzinger G, et al. Management of invasive candidiasis and candidemia in adult non-neutropenic intensive care unit patients: part I. Epidemiology and diagnosis. Intensive Care Med. 2009;35:55-62.

23. Maaroufi Y, De Bruyne JM, Duchateau V, et al. Early detection and identification of commonly encountered Candida species from simulated blood cultures by using a real-time PCR-based assay. J Mol Diagnostics. 2004:6:108-14.

24. Filioti J, Spiroglou K, Roilides E. Invasive candidiasis in pediatric intensive care patients: epidemiology, risk factors, management, and outcome. Intensive Care Med. 2007;33:1272-83.

25. Méndez-Tovar LJ, Manzano-Gayosso P, Cumplido-Uribe $C$, et al. Micosis invasivas en pacientes inmunodeprimidos con fiebre de origen desconocido. Rev Med Inst Mex Seguro Soc. 2012;50:609-14.

26. Hernández-Hernández $F$ Córdova-Martínez $E$, Manzano-Gayosso $P$ et al. Frecuencia de micosis en pacientes inmunosuprimidos de un hospital regional de la Ciudad de México. Salud Publica Mex. 2003;45:455-60.

27. González GM, Elizondo M, Ayala J. Trends in species distribution and susceptibility of bloodstream isolates of Candida collected in Monterrey, Mexico, to seven antifungal agents: results of a 3-year (2004 to 2007) surveillance study. J Clin Microbiol. 2008;46:2902-5.

28. Philip A, Odabasi Z, Matiuzzi G, et al. Syscan3, a kit for detection of anti-Candida antibodies for diagnosis of invasive candidiasis. J Clin Microbiol. 2005;43:4834-5

29. Lockhart SR, Iqbal N, Cleveland AA, et al. Species identification and antifungal susceptibility testing of Candida bloodstream isolates from population-based surveillance studies in two U. S. cities from 2008 to 2011. J Clin Microbiol. 2012;50:3435-42.

30. Quindós G. Epidemiology of candidaemia and invasive candidiasis. A changing face. Rev Iberoam Micol. 2014;31:42-8.

31. Manzano-Gayosso P, Méndez-Tovar LJ, Arenas R, et al. Levaduras causantes de onicomicosis en cuatro centros dermatológicos mexicanos y su sensibilidad antifúngica a compuestos azólicos. Rev lberoam Micol. 2011;28:32-5

32. Pfaller MA, Moet GJ, Messer SA, et al. Candida bloodstream infections: comparison of species distributions and antifungal resistance patterns in community-onset and nosocomial isolates in the SENTRY antimicrobial surveillance program, 2008-2009. Antimicrob Agents Chemother. 2011;55:561-6. 